\title{
Current State of Symptomatic Aortic Valve Stenosis in the Japanese Elderly
}

\author{
Masakazu Ohno, MD; Yuji Hashimoto, MD; Makoto Suzuki, MD; \\ Akihiko Matsumura, MD; Mitsuaki Isobe, MD
}

\begin{abstract}
Background: There have been few reports regarding treatment selection and prognosis of symptomatic aortic valve stenosis (AS) in the elderly in Japan.

Methods and Results: Sixty-one patients hospitalized between January 2000 and December 2007 for symptomatic severe AS were investigated. The average observation period was 27 months. Thirty-seven patients (61\%) were diagnosed with AS for the first time on hospitalization. Thirty-six patients had onset of symptoms within 1 month before admission. Thirty-six patients received aortic valve replacement (group $S$ ) and 25 received medical therapy (group M). The patients in group $M$ were older than those in group $S(84.1 \pm 5.3$ years vs. $74.2 \pm 4.6$ years, $P<0.001)$. Maximum flow velocity measured by echocardiography was lower in group $M(4.5 \pm 0.3 \mathrm{~m} / \mathrm{s}$ vs. $4.9 \pm 0.5 \mathrm{~m} / \mathrm{s}, P<0.01)$, but there was no difference in valve area between the 2 groups $\left(0.62 \pm 0.19 \mathrm{~cm}^{2}\right.$ vs. $\left.0.57 \pm 0.15 \mathrm{~cm}^{2}, P=0.12\right)$. One-year mortality rate derived from the Kaplan-Meier curve was higher in group $\mathrm{M}$ than group S (53.1\% vs. $6.4 \%$, respectively). On multivariate analysis, the only independent favorable prognostic factor was aortic valve replacement (HR: $0.02,95 \% \mathrm{Cl}: 0.01-0.15, \mathrm{P}<0.01)$.
\end{abstract}

Conclusions: Medical therapy is often selected for treatment of symptomatic AS in the elderly, but the prognosis is very poor. Symptomatic severe aortic stenosis should be treated surgically, or with transcatheter aortic valve implantation in cases with high surgical risk. (Circ J 2011; 75: 2474-2481)

Key Words: Aging; Aortic stenosis; Japanese; Prognosis

W ith the aging of society, the incidence rates of aortic valve stenosis (AS) accompanying degenerative changes due to aging are increasing. ${ }^{1}$ The best treatment for severe symptomatic AS is aortic valve replacement (AVR). However, it is often difficult to decide to pursue AVR in elderly patients due to the risks of various complications as well as social backgrounds.

\section{Editorial $\mathrm{p} 2324$}

There have been many reports regarding the prognosis of AVR in patients over 80 years of age. ${ }^{2-6}$ The percentages of elderly patients selected for AVR or medical therapy, along with the corresponding prognoses, were reported in a study performed in the UK. ${ }^{7}$ However, no such information is available for the Japanese population.

This study was performed to clarify the prognosis of elderly symptomatic AS patients in Japan.

\section{Methods}

\section{Study Population}

A retrospective analysis of patients admitted to our hospital for symptomatic severe AS from January 2000 to December 2007 was performed. Here, severe AS was defined as a maximum flow velocity at aortic valve measured by continuous wave Doppler from echocardiography of $4 \mathrm{~m} / \mathrm{s}$ or more. In addition, the patient must have at least one of the following symptoms: syncope, chest pain, or symptoms of heart failure corresponding to New York Heart Association (NYHA) classification class II or above.

This study was approved by the institutional review board of Kameda Medical Center.

\section{Statistical Analysis}

Continuous numerical data are expressed as the means \pm standard deviation, and group data are shown as percentages. For comparison between groups, the t-test was performed on continuous numerical data, and the chi-square test or Fisher's

Received January 6, 2011; revised manuscript received April 28, 2011; accepted May 23, 2011; released online July 23, 2011 Time for primary review: 31 days

Department of Cardiology, Kameda Medical Center, Kamogawa (M.O., Y.H., M.S., A.M.); Department of Cardiovascular Medicine, Tokyo Medical and Dental University Graduate School, Tokyo (M.O., M.I.), Japan

Mailing address: Masakazu Ohno, MD, Department of Cardiology, Kameda Medical Center, 929 Higashi-cho, Kamogawa 296-8602, Japan. E-mail: mohno@kameda.jp

ISSN-1346-9843 doi:10.1253/circj.CJ-11-0012

All rights are reserved to the Japanese Circulation Society. For permissions, please e-mail: cj@j-circ.or.jp 


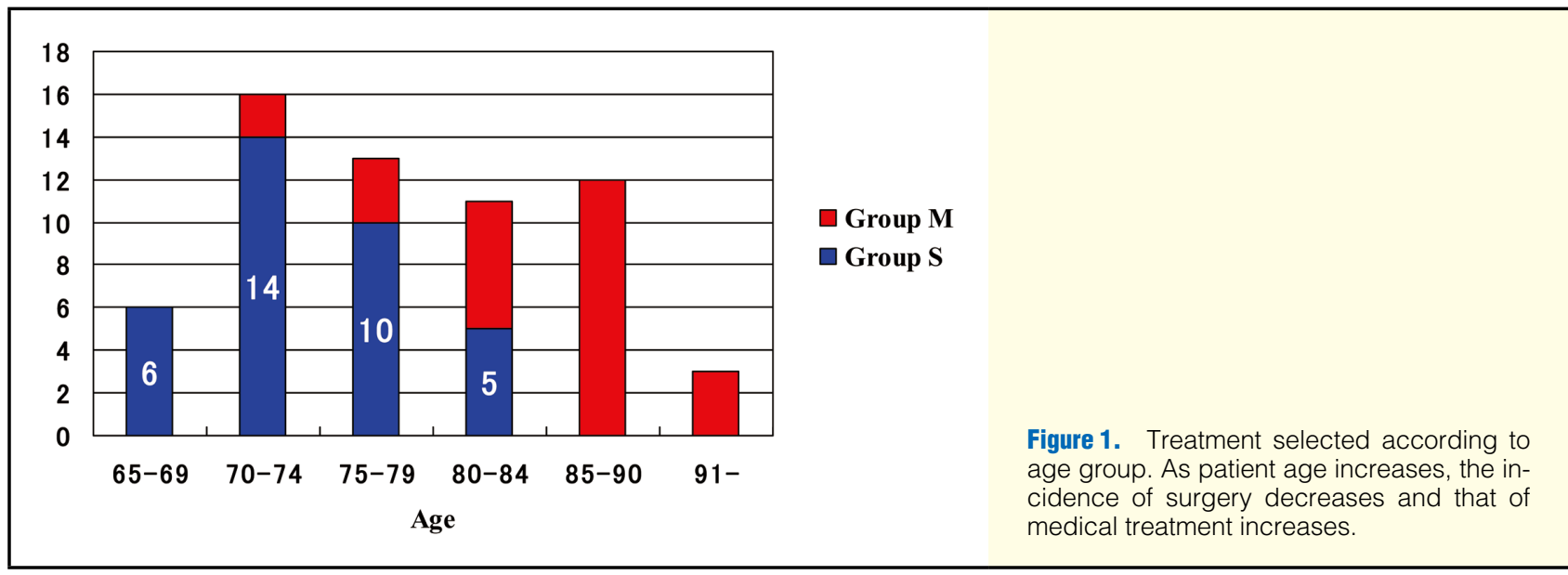

test was performed on group data. Using the Cox hazard model, univariate analysis was performed on all data, and multivariate analysis was performed using variables that were significant. Statistical analyses were performed using SPSS, Version 10.0 J (Chicago, IL, USA), and $\mathrm{P}<0.05$ was taken to indicate statistical significance.

\section{Results}

During the observation period, 61 symptomatic AS patients over the age of 65 were admitted to our hospital. The average observation period was 27.1 months (range: 0.03-90.5 months). Twenty-one of the patients were men and the remaining 40 were women. The average age of the patients was 78.4, with the oldest being 93 years old. Average maximum flow velocity was $4.7 \mathrm{~m} / \mathrm{s}$, and average aortic valve area was $0.60 \mathrm{~cm}^{2}$. Thirty-seven of the 61 patients $(61 \%)$ were diagnosed as having AS for the first time at the time of hospitalization.

Thirty-six patients had onset of symptoms within 1 month before admission, and the average symptomatic period was 5.3 months. Sixteen of the 37 patients with newly diagnosed AS had onset of symptoms more than 1 month before admission.

All patients had symptomatic severe AS, and all were considered for surgery. Surgery was performed in 35 patients who gave consent (Group S). Twenty-five patients who refused, or were thought to have high surgical risk due to underlying medical conditions, were treated medically (Group M).

The medical therapies were not standardized, and medications were prescribed at the discretion of the attending physician.

The patients in group $\mathrm{M}$ were older than those in group $\mathrm{S}$; while $80 \%$ of the patients in group $\mathrm{M}$ were over 80 years of age, only $14 \%$ of those in group $\mathrm{S}$ were over 80 . The percentage of AVR decreased with patients' age, and there were no cases in which AVR was performed in patients above the age of 85 (Figure 1).

There were no differences between groups in gender, NYHA class, or symptoms. The predicted mortality rate in the peri-operative period using logistic EuroSCORE ${ }^{8,9}$ was higher in group $\mathrm{M}$ than in group $\mathrm{S}$. Echocardiography indicated that group $\mathrm{S}$ had higher maximum flow velocity and average pressure gradient than group $\mathrm{M}$. There were no differences in valve area or left ventricular ejection rate between the 2 groups.

Blood tests showed that hemoglobin and total protein concentrations were lower in group $\mathrm{M}$ than in group $\mathrm{S}$. There were no differences in brain natriuretic peptide (BNP) levels at the time of hospitalization or in maximum or minimum values during the clinical course between the 2 groups (Table 1).

Nineteen patients in group $\mathrm{M}(73 \%)$ and 6 patients in group $\mathrm{S}(17 \%)$ died during the observation period. The causes of death in group $M$ were cardiovascular death $(n=16)$ and noncardiac death $(n=3$; specifically, malignant tumor, infectious disease, and suicide, each $n=1$ ). The causes of death in group $\mathrm{S}$ were cardiovascular death $(\mathrm{n}=3)$ and non-cardiac death $(\mathrm{n}=3$; specifically infectious disease, $\mathrm{n}=2$, and malignant tumor, $n=1)$. Mortality rates derived from the Kaplan-Meier curve were higher in group $\mathrm{M}$ than group $\mathrm{S}$ at 1 year $(53.1 \%$ vs. $6.4 \%$, respectively), 3 years $(70.7 \%$ vs. $20.4 \%$, respectively), and 5 years ( $85.4 \%$ vs. $20.4 \%$, respectively). There were significant differences in baseline characteristics between the 2 groups, and the estimated survival curves derived from age and sex applied life-table ${ }^{10,11}$ of both groups were drawn and compared. There were no significant differences in group $\mathrm{S}$, but prognosis of group $\mathrm{M}$ was significantly poorer than the estimated survival curve (Figure 2).

The re-admission rate was also significantly higher in group $\mathrm{M}$ than in group $\mathrm{S}$ (Figure 3). Only 5 of 26 patients over the age of 80 underwent AVR. Of 21 patients given medical therapy, $16(76 \%)$ died, but all of 5 patients who underwent AVR survived.

Univariate analysis was performed to determine the prognostic factors related to death (Table 2). NYHA class and symptoms were not useful as prognostic factors. Among oral medications, use of digitalis preparations was related to poorer prognosis. The strongest prognostic factor was AVR. Even in multivariate analysis, the 2 most significant factors were use of digitalis preparations and AVR.

To determine whether BNP can be used to predict prognosis, the receiver operating characteristics (ROC) curve for BNP at the time of hospitalization, maximum and minimum values were obtained, and the area under the ROC curve for the maximum BNP was $0.764(0.628-0.900$, $\mathrm{P}=0.001$ ) (Figure 4). When the cutoff was set to $1,000 \mathrm{pg} / \mathrm{ml}$, sensitivity was $78.9 \%$ and specificity was $65.7 \%$. In group $\mathrm{M}$, when the cutoff was set to $1,000 \mathrm{pg} / \mathrm{ml}$, the group below the cutoff had 3 deaths among 9 patients (33\%), and the group above the cutoff had 11 deaths among 12 patients (92\%); the group above the cutoff had a significantly higher mortality rate $(\mathrm{P}=0.02)$. In group $\mathrm{S}$, the death rates were 1 of $18(6 \%)$ and 4 of $15(27 \%)$ for the groups below and 


\begin{tabular}{|c|c|c|c|c|}
\hline & $\underset{(n=61)}{\text { All }}$ & $\begin{array}{c}\text { Group M } \\
(n=26)\end{array}$ & $\begin{array}{c}\text { Group } S \\
(n=35)\end{array}$ & $P$ value \\
\hline Age & $78.4 \pm 7.0$ & $84.1 \pm 5.3$ & $74.2 \pm 4.6$ & $<0.001$ \\
\hline Female (\%) & $40(65.6 \%)$ & $20(77 \%)$ & $20(57 \%)$ & NS \\
\hline Heart rate (beat/min) & $87.5 \pm 26.3$ & $93.3 \pm 27.2$ & $83.2 \pm 25.5$ & NS \\
\hline NYHA class & $2.9 \pm 1.0$ & $3.0 \pm 1.0$ & $2.8 \pm 1.0$ & NS \\
\hline Symptom duration (months) & $5.3 \pm 14.1$ & $6.7 \pm 20.5$ & $4.3 \pm 6.2$ & NS \\
\hline Dyspnea & $47(77.0 \%)$ & $22(84.6 \%)$ & $25(71.4 \%)$ & NS \\
\hline Syncope & $8(13.1 \%)$ & $5(19.2 \%)$ & $3(8.6 \%)$ & NS \\
\hline Chest pain & $14(23.0 \%)$ & $4(15.4 \%)$ & $10(28.6 \%)$ & NS \\
\hline Ventilation & $7(11.5 \%)$ & $3(11.5 \%)$ & $4(11.4 \%)$ & NS \\
\hline Hemodyalysis & $3(4.9 \%)$ & $2(7.7 \%)$ & $1(2.9 \%)$ & NS \\
\hline Logistic EuroSCORE (\%) & $10.1 \pm 4.5$ & $13.8 \pm 4.6$ & $7.3 \pm 2.8$ & $<0.001$ \\
\hline \multicolumn{5}{|l|}{ Echocardiography } \\
\hline Maximal transaortic valvular velocity $(\mathrm{m} / \mathrm{s})$ & $4.7 \pm 0.5$ & $4.5 \pm 0.3$ & $4.9 \pm 0.5$ & 0.001 \\
\hline Mean pressure gradient (mmHg) & $54.8 \pm 13.9$ & $47.9 \pm 7.9$ & $59.0 \pm 15.1$ & 0.004 \\
\hline Aortic valve $\left(\mathrm{cm}^{2}\right)$ & $0.60 \pm 0.18$ & $0.57 \pm 0.15$ & $0.62 \pm 0.19$ & NS \\
\hline LVDd (mm) & $48 \pm 6$ & $47 \pm 5$ & $49 \pm 8$ & NS \\
\hline LVEF (\%) & $58 \pm 12$ & $56 \pm 11$ & $59 \pm 13$ & NS \\
\hline $\mathrm{EF}<40 \%$ & $4(6.7 \%)$ & $2(8.0 \%)$ & $2(5.7 \%)$ & NS \\
\hline \multicolumn{5}{|l|}{ Laboratory test } \\
\hline $\mathrm{Hb}(\mathrm{g} / \mathrm{dl})$ & $11.8 \pm 2.3$ & $11.1 \pm 2.1$ & $12.2 \pm 2.3$ & 0.05 \\
\hline $\mathrm{TP}(\mathrm{g} / \mathrm{dl})$ & $6.8 \pm 0.6$ & $6.6 \pm 0.6$ & $7.0 \pm 0.5$ & 0.02 \\
\hline Cre $(\mathrm{mg} / \mathrm{dl})$ & $1.2 \pm 1.4$ & $1.4 \pm 1.5$ & $1.1 \pm 1.4$ & NS \\
\hline eGFR $\left(\mathrm{ml} \cdot \mathrm{min}^{-1} \cdot 1.73 \mathrm{~m}^{-2}\right)$ & $55.2 \pm 22.8$ & $49.3 \pm 22.8$ & $59.6 \pm 22.1$ & NS \\
\hline $\mathrm{TC}(\mathrm{mg} / \mathrm{dl})$ & $190 \pm 37$ & $200 \pm 42$ & $185 \pm 33$ & NS \\
\hline BNP on admission $(\mathrm{pg} / \mathrm{ml})$ & $945 \pm 936$ & $851 \pm 805$ & $1,024 \pm 104$ & NS \\
\hline Maximal BNP (pg/ml) & $1,148 \pm 953$ & $1,327 \pm 946$ & $1,035 \pm 954$ & NS \\
\hline Minimal BNP (pg/ml) & $461 \pm 602$ & $433 \pm 433$ & $479 \pm 694$ & NS \\
\hline \multicolumn{5}{|l|}{ Previous history } \\
\hline Hypertension & $36(59.0 \%)$ & $15(57.7 \%)$ & $21(60.0 \%)$ & NS \\
\hline Dyslipidemia & $28(45.9 \%)$ & $11(42.3 \%)$ & $17(48.6 \%)$ & NS \\
\hline Diabetes mellitus & $18(29.5 \%)$ & $4(15.4 \%)$ & $14(40.0 \%)$ & 0.05 \\
\hline Coronary artery disease & $9(14.8 \%)$ & $3(11.5 \%)$ & $6(17.1 \%)$ & NS \\
\hline Cerebral vascular disease & $8(13.1 \%)$ & $1(3.8 \%)$ & $7(20.0 \%)$ & NS \\
\hline Chronic kidney disease & $37(60.7 \%)$ & $19(73.1 \%)$ & $18(51.4 \%)$ & NS \\
\hline \multicolumn{5}{|l|}{ Medication } \\
\hline Diuretics & $39(63.9 \%)$ & $19(73.1 \%)$ & $20(57.1 \%)$ & NS \\
\hline Digitalis & $13(21.3 \%)$ & $5(19.2 \%)$ & $8(22.9 \%)$ & NS \\
\hline Spironolactone & $15(24.6 \%)$ & $9(34.6 \%)$ & $6(17.1 \%)$ & NS \\
\hline ACE-I/ARB & $20(32.8 \%)$ & $9(34.6 \%)$ & $11(31.4 \%)$ & NS \\
\hline Calcium channel blocker & $16(26.2 \%)$ & $4(15.4 \%)$ & $12(34.3 \%)$ & NS \\
\hline$\beta$-blocker & $8(13.1 \%)$ & $1(3.8 \%)$ & $7(20.0 \%)$ & NS \\
\hline Statin & $13(21.3 \%)$ & $6(23.1 \%)$ & 7 (20.0\%) & NS \\
\hline Aspirin & $31(50.8 \%)$ & $5(19.2 \%)$ & $26(74.3 \%)$ & $<0.01$ \\
\hline Warfarin & $13(21.3 \%)$ & $2(7.7 \%)$ & $11(31.4 \%)$ & 0.03 \\
\hline
\end{tabular}

NYHA, New York Heart Association; LVDd, left ventricular end-diastolic dimension; LVEF, left ventricular ejection fraction; $\mathrm{Hb}$, hemoglobin; TP, total protein; Cre, creatinin; eGFR, estimated glomerular filtration rate; TC, total cholesterol; BNP, B-type natriuretic peptide; ACE-I, angiotensin converting enzyme inhibitor; ARB, angiotensin II receptor blocker.

above the cutoff, respectively; the mortality rate for the group above the cutoff was higher than that below the cutoff, but the difference was not significant $(\mathrm{P}=0.07)$.

On univariate analysis, factors affecting mortality in group $\mathrm{M}$ were hypertension, dyslipidemia, diuretics, digitalis, and statin. However, on multivariate analysis, use of diuretics was the only significant risk factor (Table 3 ).

\section{Discussion}

Predictor of Prognosis in AS Patients

In this study, AVR and digitalis were strong predictors of prognosis. AS is a disease caused by mechanical stenosis of the aortic valve, and treatment involves removal of the stenosis.

The medical therapy group in the Placement of Aortic Transcatheter Valves (PARTNER) trial, ${ }^{12}$ which compared 


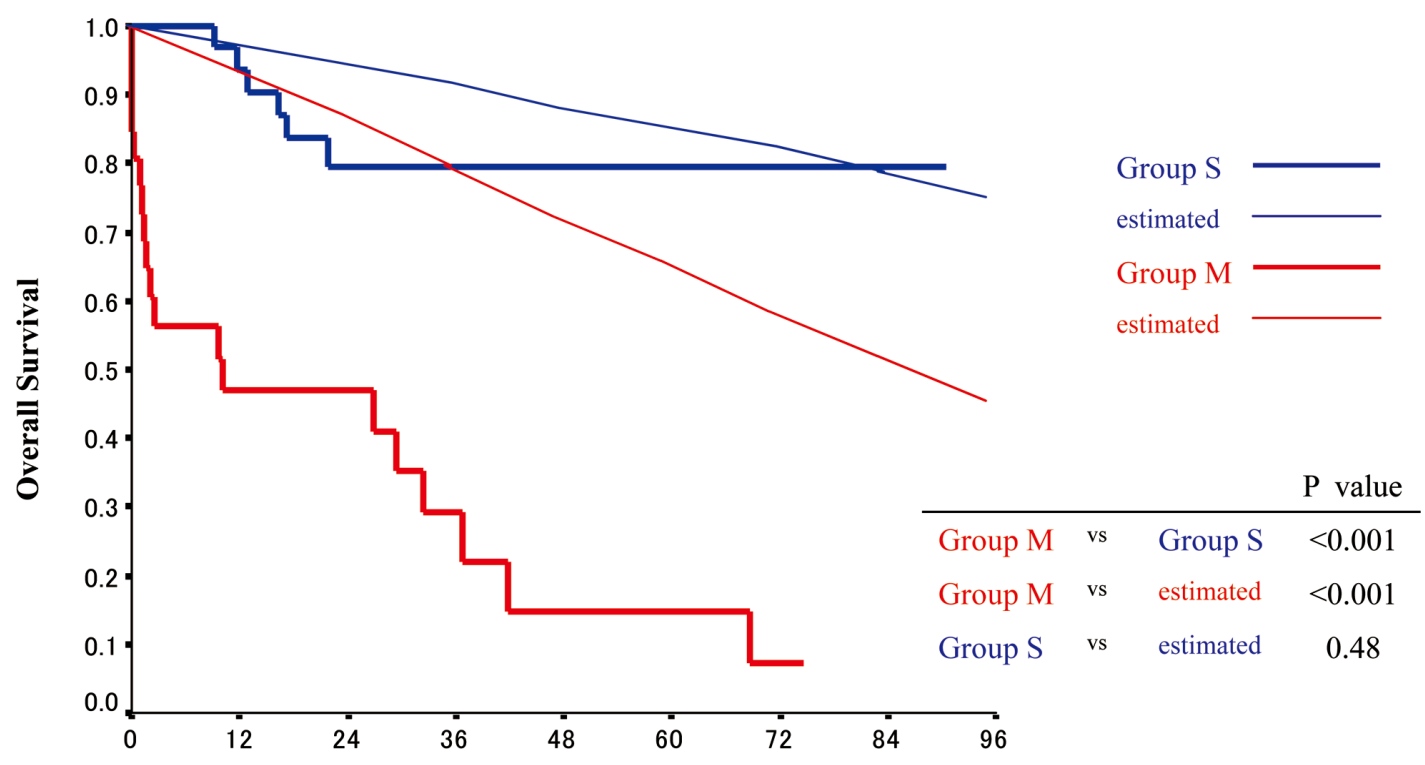

Months

No. at Risk

$\begin{array}{lllcccccc}\text { Group M } & 26 & 10 & 9 & 4 & 2 & 2 & 1 & \\ \text { Group S } & 35 & 29 & 18 & 11 & 9 & 8 & 6 & 4\end{array}$

Figure 2. Comparison of survival between Group M and Group S using Kaplan-Meier survival curve. Estimated survival curves derived from age and sex are also compared. The prognosis of group M was poorer than that of group $\mathrm{S}$ from the early stage. The prognosis of group $\mathrm{M}$ was significantly poorer than the estimated prognosis of the general population, but group $\mathrm{S}$ showed no significant difference.

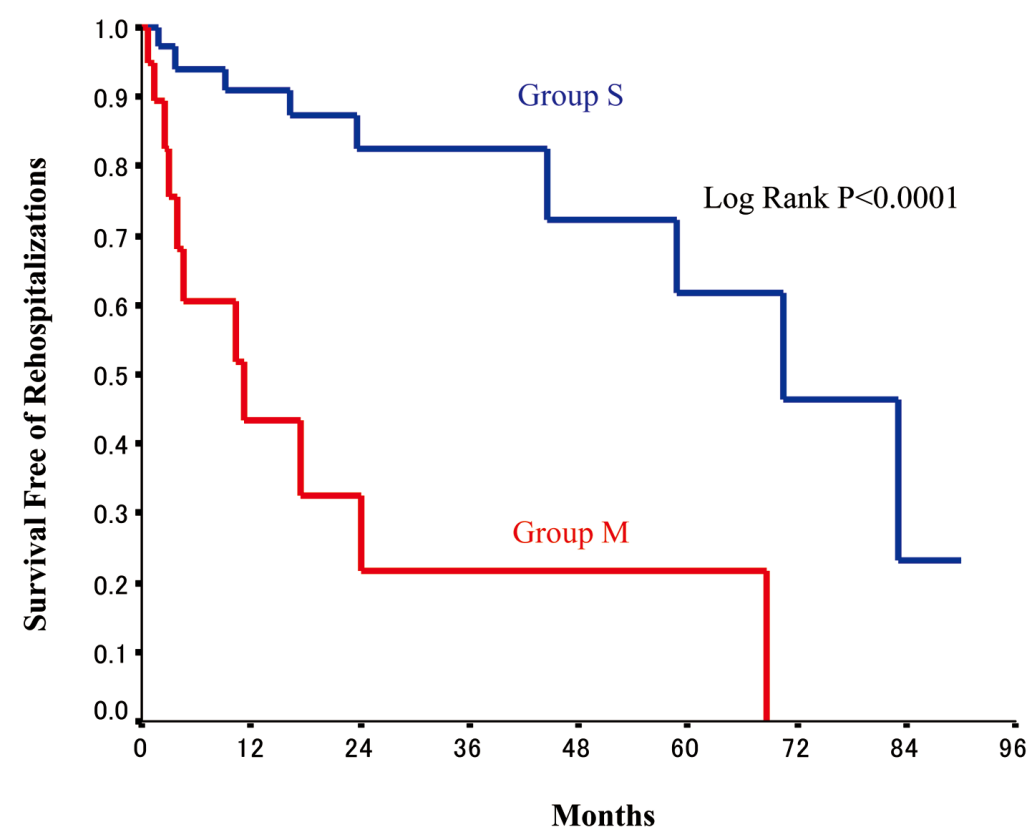

No. at Risk

$\begin{array}{ccccccccc}\text { Group M } & 26 & 5 & 3 & 1 & 1 & 1 & & \\ \text { Group S } & 35 & 27 & 16 & 10 & 7 & 6 & 3 & 1\end{array}$

Figure 3. Comparison of re-admission-free survival between Group M and Group S using Kaplan-Meier survival curve. The rate of readmission was significantly higher in group $\mathrm{M}$ than in group $S$. 


\begin{tabular}{|c|c|c|c|c|c|c|}
\hline & \multicolumn{3}{|c|}{ Univariate } & \multicolumn{3}{|c|}{ Multivariate } \\
\hline & HR & $95 \% \mathrm{Cl}$ & $P$ value & HR & $95 \% \mathrm{Cl}$ & $P$ value \\
\hline Age & 1.11 & $1.05-1.18$ & $<0.01$ & 0.90 & $0.78-1.05$ & 0.18 \\
\hline Hemodyalysis & 6.63 & $1.84-23.9$ & $<0.01$ & 0.01 & $0.01-8.59$ & 0.19 \\
\hline Logistic EuroSCORE & 1.06 & $1.01-1.12$ & 0.03 & 1.00 & $0.91-1.10$ & 0.96 \\
\hline $\mathrm{Hb}(\mathrm{g} / \mathrm{dl})$ & 0.85 & $0.73-0.99$ & 0.04 & 1.09 & $0.92-1.30$ & 0.30 \\
\hline Cre (mg/dl) & 1.30 & $1.09-1.56$ & $<0.01$ & 2.97 & $0.96-9.18$ & 0.06 \\
\hline Diabetes mellitus & 0.29 & $0.09-0.98$ & 0.05 & 0.71 & $0.17-3.03$ & 0.65 \\
\hline Digitalis & 3.57 & $1.58-8.07$ & $<0.01$ & 17.1 & $4.11-71.5$ & $<0.01$ \\
\hline AVR & 0.14 & $0.06-0.36$ & $<0.01$ & 0.02 & $0.01-0.15$ & $<0.01$ \\
\hline
\end{tabular}

$\mathrm{HR}$, hazard ratio; $\mathrm{Cl}$, confidence interval; AVR, aortic valve replacement. Other abbreviations see in Table 1.

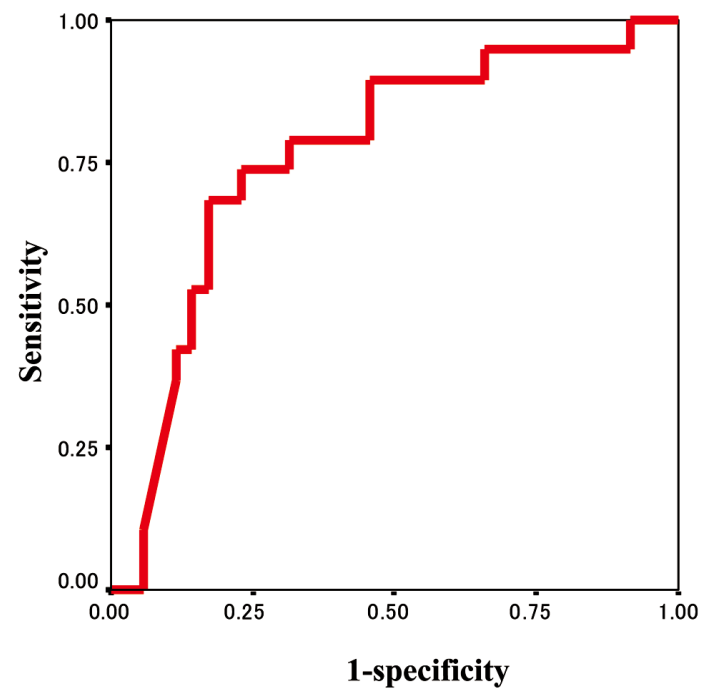

Cut off pg/ml Sensitivity \% Specificity \%

\begin{tabular}{ccc}
\hline 100 & 100.0 & 0.0 \\
300 & 94.7 & 14.3 \\
550 & 89.5 & 42.9 \\
700 & 78.9 & 54.3 \\
1000 & 78.9 & 68.6 \\
1500 & 63.2 & 82.9 \\
2000 & 10.5 & 94.3 \\
\hline
\end{tabular}

Figure 4. Receiver operating characteristics curve of death due to all causes using maximal brain natriuretic peptide as the cutoff. Sensitivity and specificity of each cutoff are also shown.

\begin{tabular}{|c|c|c|c|c|c|c|}
\hline & \multicolumn{3}{|c|}{ Univariate } & \multicolumn{3}{|c|}{ Multivariate } \\
\hline & HR & $95 \% \mathrm{Cl}$ & $P$ value & HR & $95 \% \mathrm{Cl}$ & $P$ value \\
\hline Hypertension & 0.37 & $0.14-0.98$ & 0.04 & 0.55 & $0.16-1.84$ & 0.33 \\
\hline Dyslipidemia & 0.30 & $0.10-0.94$ & 0.04 & 1.12 & $0.25-5.09$ & 0.88 \\
\hline Diuretics & 0.28 & $0.09-0.87$ & 0.03 & 0.20 & $0.05-0.77$ & 0.02 \\
\hline Digitalis & 3.36 & $1.14-9.92$ & 0.03 & 3.58 & $0.93-13.7$ & 0.06 \\
\hline Statin & 0.20 & $0.05-0.90$ & 0.04 & 0.29 & $0.06-1.53$ & 0.15 \\
\hline
\end{tabular}

Abbreviations see in Tables 1,2 .

prognosis with the transcatheter aortic valve implantation (TAVI) group, had an average age of $83.2 \pm 8.3$ years with a logistic EuroSCORE of $26.4 \pm 17.2$ and 1-year mortality rate of $50.7 \%$. Group $\mathrm{M}$ in the present study had an average age of $84.1 \pm 5.3$ with logistic EuroSCORE of $13.8 \pm 4.6$ and a 1 -year mortality rate derived from the Kaplan-Meier estimate of 53\%, which was comparable to that of the PARTNER trial.

\section{Medical Therapy}

There have been no previous reports indicating that digitalis worsens the prognosis of AS patients. Digitalis might not be responsible for worsening the prognosis by itself, but might be used in patients in poor condition for whom no other options are available.

There have been no reports of medications capable of improving the prognosis of these patients. Statins used in the treatment of dyslipidemia have been reported to slow the progress of AS, ${ }^{13}$ and several retrospective studies have shown similar results. ${ }^{14,15}$ In addition, the benefits of statins were reported in non-randomized prospective studies, ${ }^{15-17}$ and 
statins were expected to be effective in AS. However, later randomized prospective studies yielded negative results. ${ }^{18-20}$

A case with rapid progression of AS even with aggressive treatment of familial dyslipidemia has been reported in Japan. ${ }^{21}$ Differences in the mechanisms that account for oxidative stress in aortic valves and atherosclerotic arteries has been shown. ${ }^{22}$

Since the pathogenesis behind progression of AS and atherosclerosis is different, treatments to prevent progression of $\mathrm{AS}$ and atherosclerosis is also different.

To improve the prognosis, the mechanical stenosis must be removed by intervention.

\section{Age and Adaptation}

The guidelines of the Japanese Circulation Society (JCS), ${ }^{23}$ American College of Cardiology and American Heart Association (ACC/AHA), ${ }^{24}$ and the European Society of Cardiology (ESC $)^{25}$ have all stated that AVR class I is indicated in cases of symptomatic severe AS. The guidelines of the ACC/AHA and ESC also state that age is not a contraindication for surgery. The JCS Guidelines state that all cases of symptomatic severe AS with no clinical contraindications for surgery, such as the 'oldest-old', are indicated for surgery. In all of these guidelines, age alone in not a contraindication for surgery.

\section{Decision to Perform AVR}

The present study indicated the benefits of AVR even in elderly patients. However, in a daily environment in a clinical setting, it is very difficult to decide to perform AVR in an elderly patient. One reason is the high risk of surgery in elderly patients compared to younger patients. Perioperative mortality rate for AVR alone in patients in their $80 \mathrm{~s}$ was reported to be $5.0-10.3 \%,{ }^{3,5,6}$ and that for AVR with coronary artery bypass surgery $(\mathrm{CABG})$ is $6.0-26 \% .^{2,4,6}$ These numbers are high compared to the mortality rates of general AVR and AVR + CABG, which are 3.0-4.0\% and 5.0 $6.8 \%,{ }^{26,27}$ respectively.

The second reason for the reticence to perform AVR in the elderly is related to the difficulty of accurately predicting the risks during the perioperative period in individual cases. Various methods have been developed to predict mortality rate during the perioperative period, such as EuroSCORE ${ }^{8}$ that scores each item. However, in elderly patients, scoring methods have limitations, and cases with high risk, including oldest-old, were not included in the parent population used as the basis to create such scoring systems. ${ }^{6}$

The third reason is that elderly patients often have other issues, such as other organ damage, dementia, decreased activity of dailiy life, or might be a caregiver for a family member.

In many cases, the patient cannot make the decision on their own, and family members tend to avoid surgery.

\section{BNP}

BNP is useful as a prognostic factor for cardiac diseases and is also useful as a prognostic factor for AS patients. ${ }^{28,29} \mathrm{In}$ this study, patients with high BNP levels had poor prognosis, especially in the medical therapy group, and we believe that it is better to actively select surgery in such cases. However, there have been reports of cases with high BNP showing poor prognosis after surgery compared to the group with lower $\mathrm{BNP},{ }^{28,30}$ and it is therefore difficult to select surgery based only on the value of BNP.

\section{Progression of AS and Diagnosis}

It has been reported that in cases of moderate AS, the flow rate increases by $0.3 \mathrm{~m} / \mathrm{s}$, average pressure gradient increases by $7 \mathrm{mmHg}$, and valve area decreases by $0.1 \mathrm{~cm}^{2}$ every year on average. ${ }^{24}$ Measurements taken at our hospital also indicated an increase of $0.2 \pm 0.2 \mathrm{~m} / \mathrm{s}$ in flow rate, increase of $4.9 \pm 7.7 \mathrm{mmHg}$ in average pressure gradient, and decrease of $0.06 \pm 0.09 \mathrm{~cm}^{2}$ in valve area. ${ }^{31}$ It takes a few years for moderate AS to progress to the advanced stage, and it takes even longer for progression from mild to severe AS. By identifying and carefully observing AS in the early stages, AVR can be carried out at an appropriate time, when the overall condition of the patient is still good.

However, many cases are diagnosed with AS for the first time when the disease has progressed and the patient is admitted to hospital. In this study, 37 patients $(61 \%)$ were diagnosed as having AS for the first time on hospitalization. In addition, 30 of 37 patients $(80 \%)$ had been visiting medical institutions periodically for other diseases, but AS had not been noted in these cases.

To improve the prognosis, it is important to diagnose AS in the early stages, and we believe that it is necessary to introduce echocardiography, including continuous wave Doppler test, into local physical checkup in addition to auscultation.

\section{TAVI}

There are many elderly patients with symptomatic severe AS who were not diagnosed in the early stage of the disease. The efficacy of AVR in the elderly population has been reported, ${ }^{2-6}$ but the risks of surgery in this population are very high and many such patients cannot undergo the operation. ${ }^{32}$

For those at high risk for surgery, another method for intervention was introduced. TAVI, which involves the percutaneous implantation of a balloon expandable aortic valve, was first performed in human patients in $2001 .^{33}$ Self-expandable valves were first introduced in 2005, and over 15,000 patients worldwide had been treated with TAVI by April 2010. ${ }^{34}$

The antegrade approach was used initially, ${ }^{33}$ but was changed to the retrograde approach with current options of the transfemoral approach, ${ }^{35}$ subclavian/axillary approach, ${ }^{36}$ and transapical approach. ${ }^{37}$ Valve systems have also been improved by reduction in size, and retrieval became possible. ${ }^{34}$

One study ${ }^{38}$ that gathered data from several registries, in which a self-expandable valve was used, reported a success rate of approximately $98 \%$ for this procedure. All-cause mortality rate at 30 days ranged from $5.5 \%$ to $15.1 \%$. The SAPIEN Aortic Bioprosthesis European Outcome (SOURCE) Registry, ${ }^{39}$ in which a balloon expandable valve was used, showed procedural success rates of $95.2 \%$ for the transfemoral group and $92.7 \%$ for the transapical group, with mortality rates at 30 days of $6.3 \%$ and $10.3 \%$, respectively.

The PARTNER trial, ${ }^{12}$ which was a randomized controlled trial, had a rate of death from any cause, as calculated by Kaplan-Meier analysis, of $30.7 \%$ with TAVI, in comparison to $50.7 \%$ with standard therapy (hazard ratio with TAVI, 0.55).

TAVI is expected to improve the prognosis of patients with high risk of surgery.

A Japanese clinical trial called PREVAIL JAPAN ${ }^{40}$ (Transfemoral \& Transapical Placement of Aortic Balloon Expandable Transcatheter Valves Trial JAPAN) was started in April 2010, and is still underway.

If TAVI is approved in Japan, it is expected to improve the prognosis of the high-risk elderly population.

\section{Study Limitations}

This was a retrospective study at a single institution. In addition, the number of patients was small and some data were 
missing. The greatest limitation of this study was the baseline differences between the groups, including age, which prevented direct comparison of mortality rates.

\section{Conclusions}

Medical therapy is often selected for treatment of symptomatic AS in elderly patients, but its prognosis is very poor.

To improve the prognosis, it is important to identify the disease in the early stages and it is therefore necessary to introduce echocardiography into physical checkups.

In cases of severe symptomatic AS, surgery or TAVI, if the surgical risk is high, should also be indicated in elderly patients.

\section{Acknowledgments}

This study was performed with the aid of a medical research grant from Chiyoda Mutual Life Foundation.

Part of this study was presented at the $56^{\text {th }}$ and $57^{\text {th }}$ meetings of the Japanese College of Cardiology.

\section{Disclosure}

Chiyoda Mutual Life Foundation: Grant for medical research.

\section{References}

1. Otto CM, Bonow RO. Valvular heart disease. In: Braunwald E, editor. Heart disease, $8^{\text {th }}$ edn. Philadelphia: Saunders, 2008; 16251635 .

2. Akins CW, DaggetWM, Vlahakes GJ, Hilgenverg AD, Torchiana DF, Madsen JC, et al. Cardiac operations in patients 80 years old and older. Ann Thorac Surg 1997; 64: 606-614.

3. Medalion B, Lytle BW, McCarthy PM, Stewart RW, Arheart KL, Arnold JH, et al. Aortic valve replacement for octogenarians: Are small valves bad? Ann Thorac Surg 1998; 66: 699-705.

4. Kolh P, Kerzman A, Lahaye L, Gerard P, Limet R. Cardiac surgery in octogenarians: Peri-operative outcome and long-term results. Eur Heart J 2001; 22: 1235-1243.

5. Roberts WC, Ko JM, Garner WL, Filardo G, Henry AC, Hebeler RF $\mathrm{Jr}$, et al. Valve structure and survival in octogenarians having aortic valve replacement for aortic senosis (+/- aortic regurgitation) with versus without coronary artery bypass grafting at a single US medical center (1993 to 2005). Am J Cardiol 2007; 100: 489-495.

6. Iung B. Management of the elderly patient with aortic stenosis. Heart 2008; 94: 519-524.

7. Kojodjojo P, Gohil N, Barker D, Youssefi P, Salukhe TV, Choong A, et al. Outcomes of elderly patients aged 80 and over with symptomatic, severe aortic stenosis: Impact of patient's choice of refusing aortic valve replacement on survival. QJM 2008; 101: 567-573.

8. Nashef SA, Roques F, Michel P, Gauducheau E, Lemeshow S, Salamon R. European system for cardiac operative risk evaluation (EuroSCORE). Eur J Cardiotorac Surg 1999; 16: 9-13.

9. Roques F, Michel P, Goldstone AR, Nashef SA. The logistic EuroSCORE. Eur Heart J 2003; 24: 881-882.

10. Abridged Life Table for Male in 2009, Ministry of Health, Labour and Welfare. http://www.mhlw.go.jp/toukei/saikin/hw/life/life09/ hyo-m.html (accessed 15 November, 2010).

11. Abridged Life Table for Female in 2009, Ministry of Health, Labour and Welfare. http://www.mhlw.go.jp/toukei/saikin/hw/life/life09/ hyo-f.html (accessed 15 November, 2010).

12. Leon MB, Smith CR, Mack M, Miller DC, Moses JW, Svensson LG, et al. Transcatheter aortic-valve implantation for aortic stenosis in patients who cannot undergo surgery. N Engl J Med 2010; 363: $1597-1607$.

13. Aronow WS, Ahn C, Kronzon I, Goldman ME. Association of coronary risk factors and use of statins with progression of mild valvular aortic stenosis in older persons. Am J Cardiol 2001; 88: 693-695.

14. Novaro GM, Tiong IY, Pearce GL, Lauer MS, Sprecher DL, Griffin BP. Effect of hydroxymethylglutaryl coenzyme a reductase inhibitors on the progression of calcific aortic stenosis. Circulation 2001; 104: $2205-2209$.

15. Pedersen TR. Intensive lipid-lowering therapy for patients with aortic stenosis. Am J Cardiol 2008; 102: 1571-1576.

16. Bellamy MF, Pellikka PA, Klarich KW, Tajik AJ, Enriques-Sarano M. Association of cholesterol levels, hydroxymethylglutaryl coen-
zyme-A reductase inhibitor treatment, and progression of aortic stenosis in the community. J Am Coll Cardiol 2002; 40: 1723-1730.

17. Moura LM, Ramos SF, Zamorano JL, Barros IM, Azevedo LF, Rocha-Gonçalves F, et al. Rosuvastatin sffecting aortic valve endothelium to slow the progression of aortic stenosis. J Am Coll Cardiol 2007; 49: 554-561.

18. Cowell SJ, Newby DE, Prescott RJ, Bloomfiled P, Reid J, Northridge $\mathrm{DB}$, et al. A randomized trial of intensive lipid-lowering therapy in calcific aortic stenosis. N Engl J Med 2005; 352: 2389-2397.

19. Rosseb AB, Pedersen TR, Boman K, Brudi P, Chambers JB, Eqstrup $\mathrm{K}$, et al. Intensive lipid lowering with simvastatin and ezetimibe in aortic stenosis. $N$ Engl J Med 2008; 359: 1343-1356.

20. Chan KL, Teo K, Dumensnil JG, Ni A, Tam J; Astronomer investigators. Effect of lipid lowering with rosuvastatin on progression of aortic stenosis: Results of aortic stenosis progression observation: Measuring effects of rosuvastatin (ASTRONOMER) trial. Circulation 2010; 121: 306-314.

21. Tsuchida M, Kawashima MA, Tada H, Takata M, Nohara A, Ino H, et al. Marked aortic valve stenosis progression after receiving longterm aggressive cholesterol-lowering therapy using low-density lipoprotein apheresis in a patient with familial hypercholesterolemia. Circ J 2009; 73: $963-966$.

22. Heistad DD, Wakisaka Y, Miller J, Chu Y, Pena-Silva R. Novel aspects of oxidative stress in cardiovascular diseases. Circ J 2009; 73: $201-207$.

23. Guidelines for Surgical and Interventional Treatment of Valvular Heart Disease (JCS 2007). http://www.j-circ.or.jp/guideline/pdf/ JCS2007_mastuda_h.pdf (accessed 6 May, 2010).

24. Bonow RO, Carabello BA, Chatterjee K, de Leon AC Jr, Faxon DP, Freed MD, et al. 2008 focused update incorporated into the ACC/ AHA 2006 guidelines for the management of patients with valvular heart disease: A report of the American College of Cardiology/ American Heart Association Task Force on Practice Guidelines (Writing Committee to Revise the 1998 Guidelines for the Management of Patients With Valvular Heart Disease): Endorsed by the Society of Cardiovascular Anesthesiologists, Society for Cardiovascular Angioplasty and interventions, and Society of Thoracic Surgeons. Circulation 2008; 118: e523-e661.

25. Vahanian A, Baumgartner H, Bax J, Butchart E, Dion R, Filippatos $\mathrm{G}$, et al. Guidelines on the management of valvular heart disease: The Task Force on the Management of Valvular Heart Disease of the European Society of Cardiology. Euro Heart J 2007; 28: 230-268.

26. Edwards FH, Peterson ED, Coombs LP, Delong ER, Jamieson WR, Shroyer ALW, et al. Prediction of operative mortality after valve replacement surgery, J Am Coll Cardiol 2001; 37: 885-892.

27. Society of Thoracic Surgeons National Cardiac Surgery Database. http://www.sts.org/documents/pdf/ndb2010/20093rdHarvest ExecutiveSummary.pdf (accessed 6 May, 2010).

28. Bergler-Klein J, Klaar U, Heger M, Rosenhek R, Mundigler G, Gabriel $\mathrm{H}$, et al. Natriuretic peptides predict sympom-free survival and postoperative outcome in severe arotic stenosis. Circulation 2004; 109: 2302-2308.

29. Nessmith MG, Fukuta H, Brucks S, Little WC. Usefulness of an elevated B-type natriuretic peptide in predicting survival in patients with aortic stenosis treated without surgery. Am J Cardiol 2005; 96: $1445-1448$.

30. Pedrazzini GB, Masson S, Latini R, Klersy C, Rossi MG, Pasotti E, et al. Comparison of brain natriuretic peptide plasma levels versus logistic EuroSCORE in predicting in-hospital and late postoperative mortality in patients undergoing aortic valve replacement for symptomatic aortic stenosis. Am J Cardiol 2008; 102: 749-754.

31. Ohara T, Hashimoto Y, Matsumura M, Suzuki M, Isobe M. Accelerated progression and morbidity in patients with aortic stenosis on chronic dialysis. Circ J 2005; 69: $1535-1539$.

32. Iung B, Baron G, Burchart EF, Delahaye F, Gohlke-Bärwolf C, Levang OW, et al. A prospective survey of patients with valvular heart disease in Europe: The Euro Heart Survey on valvular heart disease. Eur Heart J 2003; 24: 1231 - 1243.

33. Cribier A, Eltchaninoff H, Bash A, Borenstein N, Tron C, Bauer F, et al. Percutaneous transcatheter implantaion of an aortic valve prosthesis for calcific aortic stenosis: First human case description. Circulation 2002; 106: 3006-3008.

34. Hara H, Schwarts RS. Transcatheter aortic valve implantation in high-risk patients with severe aortic stenosis. Circ J 2010; 74: 15131517

35. Webb JG, Chandavimol M, Thompson CR, Ricci DR, Carere RG, Munt BI, et al. Percutaneous aortic valve implantation retrograde from the femoral artery. Circulation 2006; 113: 842-850.

36. Petronio AS, De Carlo M, Bedogni F, Marzocchi A, Klugmann S, Maisano F, et al. Safety and efficacy of the subclavian approach for 
transcatheter aortic valve implantation with the CoreValve revalving system. Circ Cardiovasc Interv 2010; 3: 359-366.

37. Ye J, Cheung A, Lichtenstein SV, Carere RG, Thompson CR, Pasupati $\mathrm{S}$, et al. Transapical aortic valve implantation in humans. J Thorac Cardiovasc Surg 2006; 131: 1194-1196.

38. Spaccarotella C, Mongiardo A, Indolfi C. Pathophysiology of aortic stenosis and approach to treatment with percutaneous valve implantation. Circ J 2011; 75: 11-19.

39. Thomas M, Schymik G, Walther T, Himbert D, Lefèvre T, Treede
$\mathrm{H}$, et al. Thirty-day results of the SAPIEN aortic Bioprosthesis European Outcome (SOURCE) Registry: A European registry of transcatheter aortic valve implantation using the Edwards SAPIEN valve. Circulation 2010; 122: 62-69.

40. Clinical Trials.gov. Transfemoral \& Transapical Placement of Aortic Balloon Expandable Transcatheter Valves Trial (JAPAN) (PREVAIL JAPAN). http://clinicaltrials.gov/ct2/show/study/NCT01113983 (accesed 25 March, 2011). 